\title{
Composition variation and electron irradiation effects on the fluctuation conductivity in $\mathrm{Y}_{1-z} \mathrm{Pr}_{z} \mathrm{Ba}_{2} \mathrm{Cu}_{3} \mathrm{O}_{7-\delta}$ single crystals
}

\author{
A. Chroneos ${ }^{1,2, \star}$ (1), D. D. Kolesnikov ${ }^{3}$, I. A. Taranova ${ }^{3}$, A. V. Matsepulin ${ }^{3}$, and \\ R. V. Vovk ${ }^{3}$ \\ ${ }^{1}$ Department of Materials, Imperial College London, London SW7 2AZ, UK \\ ${ }^{2}$ Faculty of Engineering, Environment and Computing, Coventry University, Priory Street, Coventry CV1 5FB, UK \\ ${ }^{3}$ Physics Department, V. Karazin Kharkiv National University, Svobody Sq. 4, Kharkiv 61077, Ukraine
}

Received: 29 June 2020

Accepted: 10 September 2020

Published online:

30 September 2020

(C) The Author(s) 2020

\begin{abstract}
A comparative analysis of the changes in the fluctuation conductivity and characteristics of the superconducting state of $\mathrm{YBa}_{2} \mathrm{Cu}_{3} \mathrm{O}_{7-\delta}$ single crystals caused by various types of defects is carried out. These defects appeared due to irradiation with high-energy electrons (radiation doses from 1.4 to 8.8 $\left.10^{18} \mathrm{~cm}^{-2}\right)$, changes in oxygen deficiency $(0.08 \leq \delta \leq 0.23)$ due to annealing at different temperatures, or doping with praseodymium $\left(\mathrm{Y}_{1-z} \mathrm{Pr}_{z} \mathrm{Ba}_{2} \mathrm{Cu}_{3} \mathrm{O}_{7-\delta}\right.$, $0 \leq z \leq 0.5$ at optimal oxygen concentration). It is shown that the introduction of such defects leads to a significant expansion of the temperature range of the existence of excess conductivity, and upon doping with praseodymium, it also leads to the appearance of a thermally activated deflection on the temperature dependence of the electrical resistance. The effect of such defects on the superconducting transition temperature, $T_{c}$, and the coherence length along the $c$ axis, $\xi_{c}(0)$, is studied. In particular, $\xi_{c}(0)$ more than quadruples (at $z=0.43$ ), while the 2D-3D crossover point shifts towards higher temperatures. Possible reasons for the suppression of superconductivity in $\mathrm{YBa}_{2} \mathrm{Cu}_{3} \mathrm{O}_{7-\delta}$ upon irradiation with fast electrons and the qualitatively different temperature dependences of its resistivity in the basal plane, $\rho_{a b}(T)$, are discussed.
\end{abstract}

\section{Introduction}

Synthesis of novel superconducting materials with improved current-carrying abilities via modification of their structure and characteristics of electronic transport is one of the active research directions of modern solid state physics [1-4]. For high-temperature superconducting cuprates, the most efficient experimental approaches to accomplish this task include the introduction of artificial pinning sites [5-7] as well as the modification of their electronic

Address correspondence to E-mail: alexander.chroneos@imperial.ac.uk 
transport properties via exposure to ionizing radiation $[8,9]$ and variation of the composition [10, 11].

Among the high-temperature superconducting cuprates, compounds from the so-called 1-2-3 system, $\mathrm{RBa}_{2} \mathrm{Cu}_{3} \mathrm{O}_{7-\delta}(\mathrm{R}=\mathrm{Y}$ or another rare-earth element), are most technologically relevant for several reasons. First, these compounds have a rather high critical temperature which is above the nitrogen boiling point $[12,13]$. Second, there are well-established technologies for the fabrication of polycrystalline [14] and cast solid-phase compounds of large sizes. Finally, physical properties of these compounds can be varied via complete [15-17] or partial [18, 19] isovalent or non-isovalent substitution. The superconducting transition temperature of these optimally doped compounds amounts to $T_{c} \approx 90 \mathrm{~K}$ and it only weakly depends on the choice of $\mathrm{R}$. At the same time, it is interesting to note that $\mathrm{CeBa}_{2} \mathrm{Cu}_{3} \mathrm{O}_{7-\delta}$ and $\mathrm{TbBa}_{2} \mathrm{Cu}_{3} \mathrm{O}_{7-\delta}$ do not exhibit the orthorombic phase, $\mathrm{PmBa}_{2} \mathrm{Cu}_{3} \mathrm{O}_{7-\delta}$ is radioactive, and $\mathrm{PrBa}_{2} \mathrm{Cu}_{3} \mathrm{O}_{7-\delta}$ is not superconducting despite the orthorhombic elementary cell [20]. This is known as a praseodymium anomaly [21, 22]. In this regard, compounds with a partial substitution of $\mathrm{Y}$ for $\mathrm{Pr}$ are especially interesting as they allow one to partially suppress superconductivity while keeping the lattice parameters and the oxygen index almost unaltered. In particular, investigations of the effect of Pr impurities on the fluctuation conductivity [23] in such compounds not only contribute to the clarification of the nature of high-temperature superconductivity, but are also relevant for the elaboration of empirical ways to improve the critical parameters of high- $\mathrm{T}_{\mathrm{c}}$ superconductors.

The presence of the labile oxygen in these compounds can give rise to a non-equilibrium state [24-26]. Such a non-equilibrium state can easily be induced by high pressure $[27,28]$, abrupt temperature variations $[24,28,29]$, or appear in the course of storage or aging [30, 31]. In this regard, the use of ionizing radiation has certain advantages [32]. For instance, irradiation of YBCO with fast electrons leads to a gradual increase of the electrical resistivity and a reduction of Tc without essential alteration of the oxygen stoichiometry [33]. As for the substitution of yttrium by praseodimium [34, 35], it should be noted that Pr, in contrast to other RE elements, allows one to vary $T_{c}$ from the maximal value to zero while keeping the oxygen concentration at the optimal level [32-36]. In this way, both approaches allow one to vary the critical and electronic transport characteristics of $\mathrm{RBa}_{2} \mathrm{Cu}_{3} \mathrm{O}_{7-\delta}$ without affecting stability of the oxygen subsystem that is especially important from the viewpoint of their technological applications [14]. At the same time, the use of these approaches can noticeably affect the temperature dependence of the conductivity of these compounds, thereby creating conditions for the observation of a series of intriguing phenomena occurring in the non-superconducting state. Exemplary phenomena include the pseudogap anomaly [1, 2, 37], fluctuation paraconductivity [38, 39], metal-insulator transitions [40, 41], incoherent electronic transport [42, 43], making these studies especially important from the viewpoint of basic research [1]. According to the contemporary understanding [44], it is these phenomena which may be key to the clearing of the microscopic nature of hightemperature superconductivity, which remains unexplained despite almost 35 years of intensive experimental and theoretical investigations.

Previously, we investigated $[45,46]$ the influence of irradiation with high-energy electrons on the excess conductivity in the basal plane of optimally doped YBCO single crystals with $T_{c}=91.74 \mathrm{~K}$ and observed an essential increase of the electrical resistivity in the temperature range $T_{c}-300 \mathrm{~K}$. The increase of the resistivity was accompanied by an increase of the coherence length $\xi c(0)$ by more than a factor of 1.4. In this work, we compare the effects of electron irradiation with the influence of Pr doping and oxygen deficiency on the fluctuation conductivity and characteristics of the superconducting state in $\mathrm{YBa}_{2} \mathrm{Cu}_{3}$ $\mathrm{O}_{7-\delta}$ and $\mathrm{Y}_{1-z} \mathrm{Pr}_{z} \mathrm{Ba}_{2} \mathrm{Cu}_{3} \mathrm{O}_{7-\delta}$ single crystals. It should be noted ahead that despite extensive experimental investigations [1, 14], the mechanisms of the evolution of the different conductivity regimes in the course of irradiation of $\mathrm{RBa}_{2} \mathrm{Cu}_{3} \mathrm{O}_{7-\delta}$ compounds with electrons or variation of their elemental composition remain ultimately unclarified so far. One of the possible reasons for this can be the complexity of comparison of data for textured ceramic samples with a high content of intergranular bounds and films grown on different substrates by using different preparation techniques [14]. This is why, here, we investigate the evolution of different regimes of the fluctuation conductivity in YBCO single crystals of high structural quality, which allow for such a comparison. 


\section{Experimental}

The $\mathrm{YBa}_{2} \mathrm{Cu}_{3} \mathrm{O}_{7-\delta}$ and $\mathrm{Y}_{1-z} \mathrm{Pr}_{z} \mathrm{Ba}_{2} \mathrm{Cu}_{3} \mathrm{O}_{7-\delta}$ single crystals were grown by the solution-melt technique $[1,2,9,11,25]$ in a gold crucible. The batch consisted from $\mathrm{Y}_{2} \mathrm{O}_{3}, \mathrm{BaCO}_{3}$, and $\mathrm{CuO}$ compounds. For a partial substitution of yttrium with praseodymium in $\mathrm{Y}_{1-z} \mathrm{Pr}_{z} \mathrm{Ba}_{2} \mathrm{Cu}_{3} \mathrm{O}_{7-\delta}$ single crystals, the respective percentage of $\operatorname{Pr}_{5} \mathrm{O}_{11}$ was added to the batch. The conditions for growth and saturation with oxygen were the same for both crystal types [47]. For the optimal saturation of the crystals with oxygen, 01 , the crystals were annealed in an oxygen flow at a temperature of $703 \mathrm{~K}$ for 4 days.

All investigated crystals were twinned with the twin planes exhibiting a block structure. Electrical resistance measurements were done in the standard four-probe geometry. The typical crystal sizes were $(1.5-2) \times(0.2-0.3) \times(0.01-0.02) \mathrm{mm}^{3}$, where the smallest size corresponds to the $c$ axis. The transport current was applied along the longest side. The distance between the voltage leads amounted to $1 \mathrm{~mm}$. Irradiation of the samples with electrons at $0.5-2.5 \mathrm{meV}$ energies was done at $T<10 \mathrm{~K}$ in a special helium cryostat with a beamline inlet. The irradiation dose $D=10^{18} \mathrm{~cm}^{-2}$ corresponds to an averaged overall sublattices concentration of defects of $10^{-4}$ displacements per atom $[45,46]$. All resistance measurements were done at a fixed temperature. The temperature was measured with a platinum resistance thermometer. The temperature stability was about $5 \mathrm{mK}$.

\section{Results}

Figure 1a-c show the electrical resistance dependences on the concentration of defects that arise due to irradiation, oxygen deficiency, or doping with praseodymium.

Figure 1a displays the temperature dependences of the basal-plane electrical resistivity $\rho(T)$ measured before irradiation with fast electrons and after irradiation with different doses $D=(0 \ldots 8.8) \cdot 10^{18} \mathrm{~cm}^{-2}$. Figure $1 \mathrm{~b}$ presents the $\rho(T)$ curves in the original state and after reduction of the oxygen content $(\delta=0.08 \ldots 0.23)$ at different annealing temperatures. The temperature dependences of the basal-plane resistivity $\rho(T)$ of the optimally doped $\mathrm{Y}_{1-z} \mathrm{Pr}_{z} \mathrm{Ba}_{2-}$ $\mathrm{Cu}_{3} \mathrm{O}_{7-\mathrm{o}}$ single crystals $(0.0 \leq z \leq 0.43)$ are presented in Fig. 1c. With an increase in the concentration of defects (which is characterized by the radiation dose, oxygen deficiency or praseodymium content), the $\rho(T)$ shape is quasi-metallic [48]; the absolute values of electrical resistance are increasing, if the temperature rises, while the region of the linear dependence of $\rho(T)$ at high temperatures is narrowing.

Figures $1 \mathrm{~d}-\mathrm{f}$ shows the corresponding derivatives, $\mathrm{d} \rho(\mathrm{T}) / \mathrm{dT}$, in the region of the SC transition. It is seen that these derivatives pass through the maxima, the position of which we identify with $T_{c}$. With an increase in the defect concentration, the $\mathrm{d} \rho(T) / \mathrm{dT}$ maxima shift to the region of lower temperatures, demonstrating a tendency towards a decrease in height and an increase in width of the originally narrow superconducting transition with $\Delta T_{c} \leq 0.3 \mathrm{~K}$.

Figure $1 \mathrm{~g}-\mathrm{i}$, which are derived from Fig. $1 \mathrm{a}-\mathrm{c}$ and $\mathrm{d}-\mathrm{f}$, show the dependences of $T_{c}$ and $\rho(300 \mathrm{~K})$ on the concentration of defects (see also Table 1). It can be seen that, in the case of electron irradiation, a decrease in $T_{c}$ to $86 \mathrm{~K}$ corresponds to the largest change in $\rho(300 \mathrm{~K})$, and in the case of an increase in oxygen deficiency, the change in $\rho(300 \mathrm{~K})$ is the smallest, that is, $\Delta \rho^{86}{ }_{\text {irr }}(300 \mathrm{~K})>\Delta \rho^{86}{ }_{\operatorname{Pr}}(300-$ $\mathrm{K})>\Delta \rho^{86} \delta(300 \mathrm{~K})$. Thus, $T_{c}$ demonstrates the highest resistance to defects caused by irradiation with highenergy electrons.

Note that a decrease in $T_{c}$ to $86 \mathrm{~K}$ and a corresponding increase in $\rho$ in the range $T_{c}-300 \mathrm{~K}$ in the case of electron irradiation is not accompanied by a change in the shape of the $\rho(T)$ curve. At the same time, a decrease in the oxygen concentration or doping with praseodymium causes the appearance of an S-shaped thermally activated bending of $\rho(T)$. The thermally activated behavior of $\rho(T)$ for irradiated samples manifests itself only at sufficiently low values of $T_{c}$ [40] and can be associated with the appearance of dielectric inclusions caused by the redistribution of oxygen between the $\mathrm{O}(4)$ and $\mathrm{O}(5)$ positions (in the notation [5]) [49] and the formation of local regions with a tetragonal phase.

In samples with a low oxygen concentration, the SC transition acquires a step-like shape-curves $1-5$ as in Fig. 1b, which may indicate the presence of several phases with different $T_{c}$ [48].

The temperature dependences of the basal-plane resistivity $(T)$ of the $\mathrm{Y}_{1-z} \mathrm{Pr}_{z} \mathrm{Ba}_{2} \mathrm{Cu}_{3} \mathrm{O}_{7-\delta}$ single crystals are presented in Fig. 1c. As it follows from Fig. 1c and Table 1, $\rho$ increases with increase of the Pr concentration, while $T_{c}$ is decreasing. These observations 

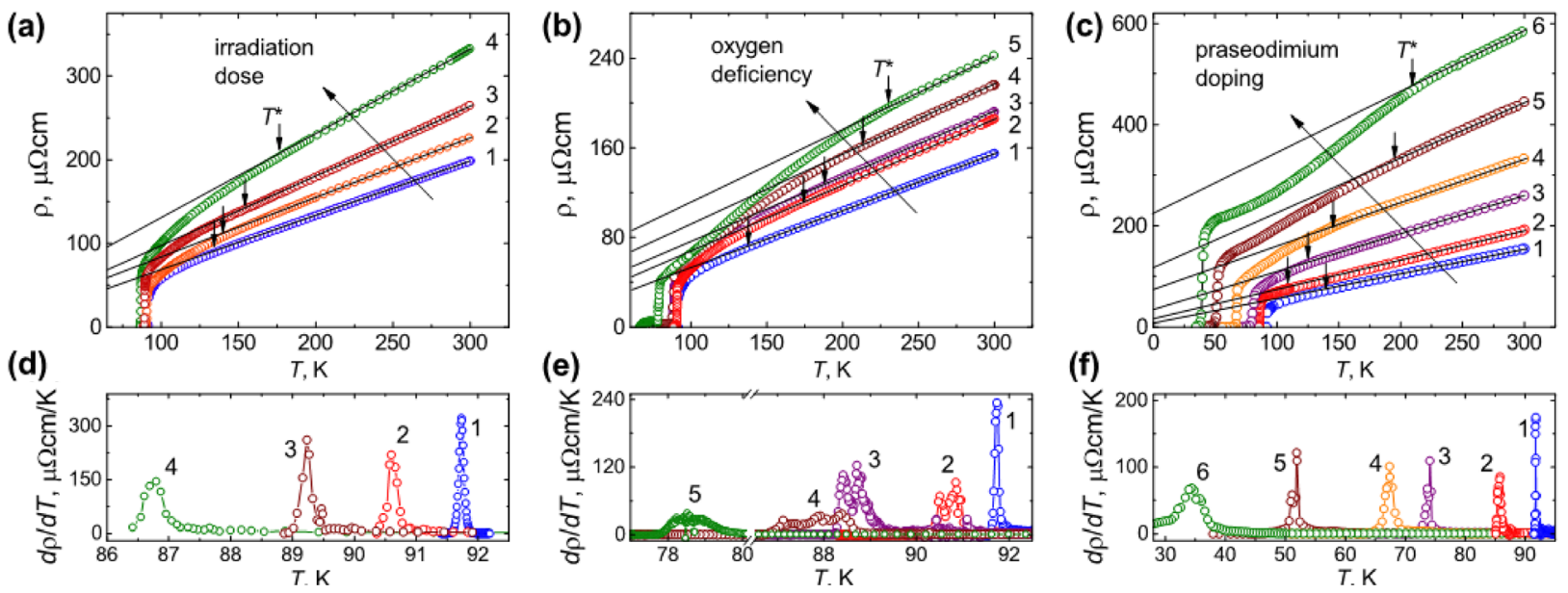

(g)

(h)
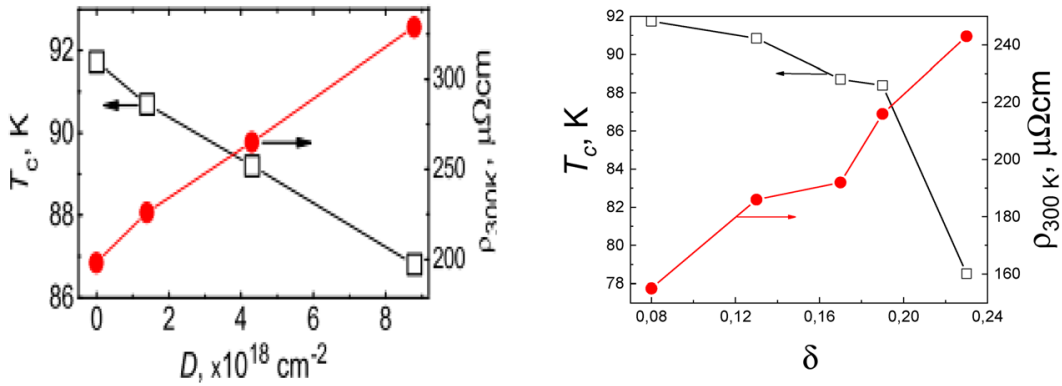

(i)

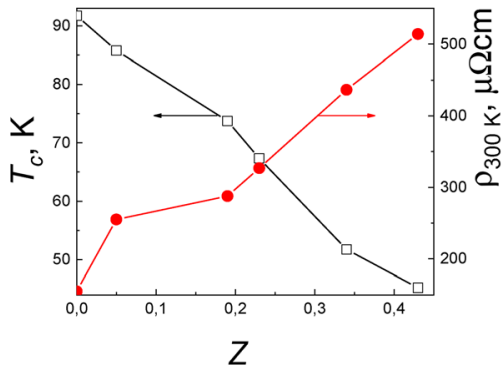

Fig. 1 Series of representative temperature dependences of the basal-plane electrical resistivity $\rho(T)$ of the $\mathrm{YBa}_{2} \mathrm{Cu}_{3} \mathrm{O}_{7-\delta}$ single crystals. a Before (1) and after (2-4) irradiation with fast electrons. b Before (1) and after (2-5) step-by-step annealing leading to an increase of the oxygen deficiency. c For samples with different contents of praseodymium. $\mathbf{d}-\mathbf{f}$ The respective resistive transitions

are in agreement with the literature [1,24]. It is worth noting that for Pr concentrations $0.0 \leq z \leq 0.34$, the $\rho(\mathrm{T})$ curves are quasi-metallic, while with a further increase of the $\operatorname{Pr}$ concentration, $\rho(T)$ exhibits a characteristic S-shaped bending.

As one sees in Fig. 1, below some characteristic temperature $T^{*}$, the $\rho(T)$ curves begin to deviate from the linear law that can be attributed to an excess conductivity. Its temperature dependence can be determined from the following expression:

$\Delta \sigma=\sigma-\sigma_{0}$

where $\sigma_{0}=\rho_{0}{ }^{-1}=(\mathrm{A}+\mathrm{BT})^{-1}$ is the conductivity determined by the interpolation of the linear hightemperature section of $\rho(T)$ towards zero temperature and $\sigma=\rho^{-1}$ is the measured conductivity value at $T<T^{*}$. As is known, near $T_{c}$, the excess conductivity is caused by the fluctuational pairing of charge carriers and it can be described by a power-law in the $\mathrm{d} \rho / \mathrm{dT}$ versus $\mathrm{T}$ representation. $\mathbf{g}-\mathbf{i}$ Dependences of the superconducting transition temperature $T_{c}$ and the resistivity at room temperature, $\rho(300 \mathrm{~K})$, on the irradiation dose $D$, oxygen index $\delta$, and the $\operatorname{Pr}$ content $z$. Curve numbering is consistent within each panel column. Arrows indicate the temperature $T^{*}$ at which the $\rho(T)$ curves begin to deviate from the linear dependence

dependence obtained within the framework of the Lawrence-Doniach model [50]. This model implies a gradual crossover from the $2 \mathrm{D}$ to $3 \mathrm{D}$ regime of the fluctuation conductivity with decrease of the temperature.

$\Delta \sigma=\left[\frac{e^{2}}{16 \eta d}\right] \varepsilon^{-1}\left\{1+J \varepsilon^{-1}\right\}^{-1 / 2}$,

where $\varepsilon=\left(T-T^{\mathrm{mf}}\right) / T^{\mathrm{mf}}{ }_{\mathrm{c}}$ is the reduced temperature, $T^{\mathrm{mf}}{ }_{\mathrm{c}}$ is the critical temperature in the mean-field approximation, $J=(2 \xi c(0) / d)^{2}$ is the interlayer pairing constant, $\xi_{c}$ is the coherence length along the $c$ axis, and $d$ is the thickness of the 2D layer. In the limiting case $T \rightarrow T_{c}$, the interaction between the fluctuational Cooper pairs takes place in the entire volume of the superconductor as $\xi c \gg d$ and the conductivity is in the 3D regime. In the opposite limiting case $T \gg T_{c}$, pairing of charge carriers is only possible within the layers as $\xi c \ll d$ and the conductivity is in 
Table 1 Evolution of the resistive and superconducting properties of the

$\mathrm{YBa}_{2} \mathrm{Cu}_{3} \mathrm{O}_{7-\delta}$ single crystals in the course of irradiation with fast electrons, annealing at different temperatures, and doping with praseodimium

\begin{tabular}{lcllllll}
\hline Variable & $T_{\mathrm{c}}, \mathrm{K}$ & $\rho(300 \mathrm{~K}), \mu \Omega \mathrm{cm}$ & $T^{*}, \mathrm{~K}$ & $\alpha_{1}$ & $\alpha_{2}$ & $\varepsilon_{0}$ & $\xi_{\mathrm{c}}(0), \AA$ \\
\hline $\mathrm{YBa}_{2} \mathrm{Cu}_{3} \mathrm{O}_{7-\delta}$ & single crystal before and after irradiation & with the irradiation dose $\mathrm{D}$ \\
$\mathrm{D}=0$ & 91.74 & 199 & 137 & -0.501 & -1.044 & 0.064 & 1.44 \\
$1.4 \cdot 10^{18} \mathrm{~cm}^{-2}$ & 90.60 & 227 & 143 & -0.499 & -1.032 & 0.094 & 1.79 \\
$4.4 \cdot 10^{18} \mathrm{~cm}^{-2}$ & 89.24 & 267 & 156 & -0.503 & -1.009 & 0.097 & 1.82 \\
$8.8 \cdot 10^{18} \mathrm{~cm}^{-2}$ & 86.79 & 332 & 175 & -0.491 & -1.015 & 0.125 & 2.07 \\
$\mathrm{YBa}_{2} \mathrm{Cu}_{3} \mathrm{O}_{7-\delta}$ single crystal before and after annealing at different temperatures & & \\
$7-\delta=6.92$ & 91.738 & 155 & 143 & -0.499 & -1.012 & 0.064 & 1.48 \\
6.87 & 90.845 & 186 & 171 & -0.496 & -1.032 & 0.104 & 1.89 \\
6.83 & 88.712 & 192 & 192 & -0.500 & -1.005 & 0.145 & 2.23 \\
6.81 & 88.394 & 216 & 215 & -0.499 & -1.010 & 0.206 & 2.65 \\
6.77 & 78.515 & 243 & 232 & -0.505 & -1.031 & 0.292 & 3.17 \\
$\mathrm{Y}_{1-\mathrm{z}} \mathrm{Pr}_{\mathrm{z}} \mathrm{Ba}_{2} \mathrm{Cu}_{3} \mathrm{O}_{7-\delta}$ single crystal with different concentrations of praseodimium & & \\
$z=0$ & 91.74 & 155 & 143 & -0.499 & -1.012 & 0.064 & 1.48 \\
0.05 & 85.78 & 255 & 110 & -0.528 & -1.039 & 0.067 & 1.51 \\
0.19 & 73.75 & 287.78 & 127 & -0.504 & -1.017 & 0.111 & 1.95 \\
0.23 & 67.33 & 326.89 & 137.5 & -0.501 & -1.023 & 0.242 & 2.88 \\
0.34 & 51.74 & 436.43 & 187 & -0.492 & -1.042 & 0.64 & 4.68 \\
0.43 & 45.2 & 514.04 & 219 & -0.495 & -1.017 & 1.381 & 6.875 \\
\hline
\end{tabular}

the 2D regime. Accordingly, Eq. (2) can be transformed into the well-known Aslamazov-Larkin relation [51] for the 2D and 3D limiting cases

$\Delta \sigma_{2 D}=\frac{e^{2}}{16 \eta d} \varepsilon^{-1}$

and

$\Delta \sigma_{3 D}=\frac{e^{2}}{32 \eta \xi_{c}(0)} \varepsilon^{-1 / 2}$

For a comparison of these relations with experimental data one needs to accurately determine $T^{\mathrm{mf}}{ }_{\mathrm{c}}$ as it strongly affects the slope of the $\Delta \sigma(\varepsilon)$ dependences. The quantities $\xi c(0), d$, and $T_{c}$ in Eqs. (2)-(4) are usually varied as fitting parameters [38]. However, comparison of theory with experiment yields a rather poor quantitative agreement when one uses such an approach. At the same time, the introduction of an additional scaling parameter, the so-called C-factor, allows one to account for a possible inhomogeneous current distribution in the sample volume and to thereby fit experimental data better to the theoretical expressions. In our analysis, we followed the suggestion [10] to use for $T^{\mathrm{mf}}$ the $T_{c}$ values deduced at the maxima of the $\mathrm{d} \rho / \mathrm{dT}$ derivatives, as illustrated in Fig. 1d, e, f.

Figure 2 displays the temperature dependences $\Delta \sigma(T)$ in the double logarithm representation. One sees that in the temperature range between $T_{c}$ and $1.1-1.25 T_{c}$ (depending on the oxygen concentration) these dependences can be satisfactorily fit by straight lines with the slopes $\alpha_{1} \approx-0.5$. This slope $\mathrm{P}$ corresponds to the exponent $-1 / 2$ in Eq. (4) that attests the $3 \mathrm{D}$ character of the fluctuation conductivity in this temperature range. With a further decrease of the temperature, the decrease rate of $\Delta \sigma$ strongly increases $\left(\alpha_{2} \approx-1\right)$ that, in turn, points to a dimensionality change in the fluctuation conductivity. As it follows from Eqs. (3) and (4), at the 2D-3D crossover point one has.

$\varepsilon_{0}=4\left[\xi_{\mathrm{c}}(0) / d\right]^{2}$

With the $\varepsilon_{0}$ values thus deduced and the literature data for the dependence of the interlayer distance $d$ on $\delta[52,53]$ one can calculate $\xi_{c}(0)$. As it follows from Table 1, $\xi_{c}(0)$ calculated by using Eq. (5) increases from $1.44 \AA$ to $2.07 \AA$ with decrease of $T_{c}$. This observation is in a qualitative agreement with the dependence of $\xi c(0)$ on $\delta$ obtained for $\mathrm{YBCO}$ samples [48] in the course of a step-by-step decrease of the oxygen concentration and increase of the praseodimium content $[19,34]$.

As noted above, with decrease of the temperature below some characteristic value $T^{*}$, one observes a deviation of $\rho(T)$ from the linear dependence $[1,2,37]$. This deviation attests to the appearance of the excess conductivity which is caused by a 
(a)

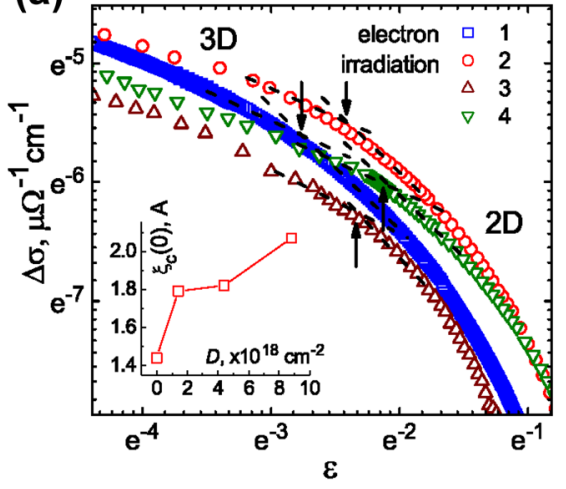

(b)

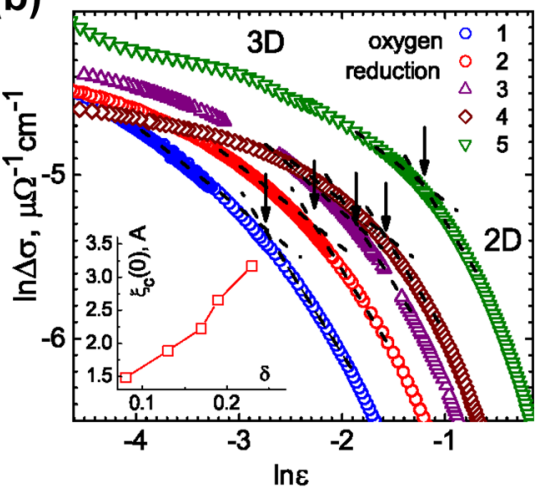

(c)

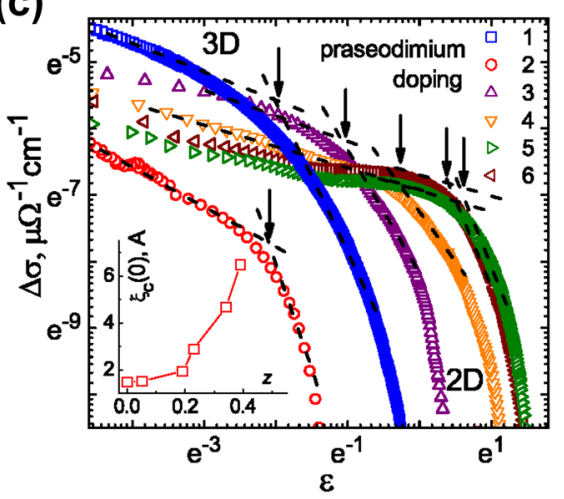

Fig. 2 Dependences $\Delta \sigma(\mathrm{T})$ in the double logarithm representation. Curve numbering is the same as in Fig. 1. Insets: Dependence of $\xi \mathrm{c}$ on the irradiation dose $D$ and the concentrations of oxygen, and praseodimium

transition to the pseudogap regime $[29,54]$. Specifically, for the sample with $\operatorname{Pr}$ concentrations $z \leq 0.05$, the linear section of $\rho(\mathrm{T})$ is expanding as compared to the reference $\mathrm{YBa}_{2} \mathrm{Cu}_{3} \mathrm{O}_{7-\delta}$ single crystal, while $\mathrm{T}^{*}$ shifts towards lower temperatures by more than $30 \mathrm{~K}$. This, in return, points to the narrowing of the temperature range in which the excess conductivity exists. Such a behavior is rather unusual because at $\mathrm{Pr}$ concentrations $z \geq 0.2$ an inverse shift of $T^{*}$ towards higher temperatures is observed [19].

It should be noted that the essential extension of the excess conductivity regime to $T>1.5 T_{c}$ cannot be, probably, explained within the framework of the existing fluctuational theories. According to the contemporary knowledge (see, for instance $[1,2,37])$, such a behavior of $\rho(T)$ can be caused by a transition to the so-called pseudogap state which is peculiar to underdoped high-temperature superconducting compounds. At the same time, one should not rule out that the mentioned peculiarity can also partially be caused by the presence of an additive contribution to the conductivity of impurity phases with a higher $T_{c}$. As it was shown already in early works devoted to investigations of the fluctuation conductivity in high-temperature superconducting compounds [20], while at normal conditions superconducting phases with $T_{c}<140 \mathrm{~K}$ are structurally unstable, they still can exist as impurity phases in alloyed and multi-phase samples. A certain role in these can be played by specific quasiparticle scattering mechanisms [55-59] caused by the presence of structural and kinematic anisotropy in the system.

\section{Conclusion}

To summarize, we can say that the evolution of the excess conductivity of $\mathrm{YBa}_{2} \mathrm{Cu}_{3} \mathrm{O}_{7-\delta}$ single crystals was studied during irradiation with fast electrons, a decrease in the oxygen concentration, and an increase in the praseodymium content.

In all cases, qualitatively similar effects are observed, namely, the temperature range of the excess conductivity regime expands, $T_{c}$ decreases, the coherence length increases, and the 2D-3D crossover point shifts towards higher temperatures.

With the same changes in $T_{c}$, electron irradiation is accompanied by the largest changes in the magnitude of the normal resistance, $\rho_{a b}(300 \mathrm{~K})$, and the smallest changes in the coherence length, $\xi_{c}(0)$, compared to the effect of the composition (oxygen deficiency or praseodymium), that is, the SC state is more resistant to defects caused by irradiation than oxygen deficiency or praseodymium. One of the possible reasons leading to this may be the appearance of radiation-induced insulating inclusions caused by the redistribution of oxygen between the $O(4)$ and $O(5)$ positions, and the formation of local regions with a tetragonal structure, which are shunted by the initial superconductor. 
At the same time, changes in the composition lead to a change in the shape of the $\rho(T)$ curves, up to an $S$ shape (thermally activated bend), in the case of doping with praseodymium.

Open Access This article is licensed under a Creative Commons Attribution 4.0 International License, which permits use, sharing, adaptation, distribution and reproduction in any medium or format, as long as you give appropriate credit to the original author(s) and the source, provide a link to the Creative Commons licence, and indicate if changes were made. The images or other third party material in this article are included in the article's Creative Commons licence, unless indicated otherwise in a credit line to the material. If material is not included in the article's Creative Commons licence and your intended use is not permitted by statutory regulation or exceeds the permitted use, you will need to obtain permission directly from the copyright holder. To view a copy of this licence, visit http://creativecommons.org/licen ses/by/4.0/.

\section{References}

1. R.V. Vovk, A.L. Solovjov, Low Temp. Phys. 44(2), 81 (2018). https://doi.org/10.1063/1.5020905

2. A.L. Solovjov, E.V. Petrenko, L.V. Omelchenko, R.V. Vovk, I.L. Goulatis, A. Chroneos, Sci. Rep. 9(1), 9274 (2019). h ttps://doi.org/10.1038/s41598-019-45286-w

3. O.V. Dobrovolskiy, M. Huth, V. Shklovskij, R.V. Vovk, Sci. Rep. 7, 13740 (2017). https://doi.org/10.1038/s41598-017-1 4232-z

4. O.V. Dobrovolskiy, V.M. Bevz, E. Begun, R. Sachser, R.V. Vovk, M. Huth, Phys. Rev. Appl. 11, 054064 (2019). https://d oi.org/10.1103/PhysRevApplied.11.054064

5. G. Blatter et al., Rev. Mod. Phys. 66, 1125 (1994)

6. A.V. Bondarenko, V.A. Shklovskij, M.A. Obolenskii, R.V. Vovk, A.A. Prodan, M. Pissa, D. Niarchos, G. Kallias, Phys. Rev. B. 58(5), 2445-2447 (1998)

7. A.V. Bondarenko, A.A. Prodan, M.A. Obolenskii, R.V. Vovk, T.R. Arouri, Low Temp. Phys. 27(5), 339-344 (2001)

8. F. Rullier-Albenque, H. Alloul, R. Tourbot, Phys. Rev. Lett. 91, 047001 (2003). https://doi.org/10.1103/PhysRevLett.91. 047001

9. N.A. Azarenkov, V.N. Voevodin, R.V. Vovk, G.Y. Khadzhai, S.V. Lebedev, V.V. Sklyar, S.N. Kamchatnaya, O.V. Dobrovolskiy, J. Mater. Sci. Mater. Electron. 28, 15886 (2017). h ttps://doi.org/10.1007/s10854-017-7483-4
10. H.A. Borges, M.A. Continentino, Solid State Commun. 80(3), 197 (1991). https://doi.org/10.1016/0038-1098(91)90180-4

11. R. Vovk, M. Obolenskii, A. Zavgorodniy, A. Bondarenko, I. Goulatis, A. Chroneos, J. Mater. Sci. Mater. Electron. 18(8), 811 (2007). https://doi.org/10.1007/s10854-006-9086-3

12. M.K. Wu, J.R. Ashburn, C.J. Torng, P.H. Hor, R.L. Meng, L. Gao, Z.J. Huang, Y.Q. Wang, C.W. Chu, Phys. Rev. Lett. 58, 908 (1987). https://doi.org/10.1103/PhysRevLett.58.908

13. R.V. Vovk, N.R. Vovk, G.Y. Khadzhai, I.L. Goulatis, A. Chroneos, Phys. B 422, 33 (2013). https://doi.org/10.1016/j. physb.2013.04.032

14. T. Timusk, B. Statt, Rep. Prog. Phys. 62(1), 61 (1999)

15. M. Akhavan, Phys. B 321(1-4), 265 (2002). https://doi.org/ 10.1016/S0921-4526(02)00860-8

16. R.V. Vovk, M.A. Obolenskii, A.A. Zavgorodniy, I.L. Goulatis, A. Chroneos, E.V. Biletskiy, J. Alloy Compd. 485, L21 (2009). https://doi.org/10.1016/j.jallcom.2009.05.132

17. R.V. Vovk, M.A. Obolenskii, A.A. Zavgorodniy, I.L. Goulatis, V.I. Beletskii, A. Chroneos, Phys. C 469, 203-206 (2009)

18. R.V. Vovk, M.A. Obolenskii, A.A. Zavgorodniy, Z.F. Nazyrov, I.L. Goulatis, V.V. Kruglyak, A. Chroneos, Modern Phys. Lett. B MPLB 25(27), 2131-2136 (2011)

19. R.V. Vovk, M.A. Obolenskii, A.A. Zavgorodniy, D.A. Lotnyk, K.A. Kotvitskaya, Phys. B 404(20), 3516 (2009). http s://doi.org/10.1016/j.physb.2009.05.047

20. D.M. Ginsberg (ed.), Physical Properties of High Temperature Superconductors I (Word Scientific, Singapore, 1989)

21. R.V. Vovk, N.R. Vovk, O.V. Shekhovtsov, I.L. Goulatis, A. Chroneos, Supercond. Sci. Technol. 26, 085017 (2013)

22. A. Chroneos, I.L. Goulatis, R.V. Vovk, Acta Chim. Slov. 54, 179 (2007)

23. A.L. Solovjov, L.V. Omelchenko, E.V. Petrenko, R.V. Vovk, V.V. Khotkevych, A. Chroneos, Sci. Rep. 9(1), 20424 (2019). https://doi.org/10.1038/s41598-019-55959-1

24. K. Widder, A. Zibold, M. Merz, H. Geserich, A. Erb, G. Müuller-Vogt, Phys. C 232(1-2), 82 (1994). https://doi.org/ 10.1016/0921-4534(94)90296-8

25. M.A. Obolenskii, A.V. Bondarenko, R.V. Vovk, A.A. Prodan, Low Temp. Phys. 23(11), 882 (1997). https://doi.org/10.1063/ 1.593496

26. R. Vovk, N. Vovk, A. Samoilov, I. Goulatis, A. Chroneos, Solid State Commun. 170, 6 (2013). https://doi.org/10.1016/j. ssc.2013.07.011

27. R.P. Gupta, M. Gupta, Phys. Rev. B Condens. Matter 51, 11760 (1995). https://doi.org/10.1103/PhysRevB.51.11760

28. D.D. Balla, A.V. Bondarenko, R.V. Vovk, M.A. Obolenskii, A.A. Prodan, Low Temp. Phys. 23(10), 777 (1997). https://d oi.org/10.1063/1.593445 
29. J.D. Jorgensen, S. Pei, P. Lightfoor, H. Shi, A.P. Paulikas, B.W. Veal, Phys. C 167(5-6), 571 (1990). https://doi.org/10. 1016/0921-4534(90)90676-6

30. B. Martınez, F. Sandiumenge, S. Pinol, N. Vilalta, J. Fontcuberta, X. Obradors, Appl. Phys. Lett. 66(6), 772 (1995). https://doi.org/10.1063/1.114089

31. R. Vovk, N. Vovk, G. Khadzhai, O. Dobrovolskiy, Z. Nazyrov, J. Mater. Sci. Mater. Electron. 25(12), 5226 (2014). h ttps://doi.org/10.1007/s10854-014-2292-5

32. J. Giapintzakis, D.M. Ginsberg, M.A. Kirk, S. Ockers, Phys. Rev. B Condens. Matter 50, 15967 (1994). https://doi.org/10. 1103/PhysRevB.50.15967

33. A.V. Bondarenko, A.A. Prodan, Y.T. Petrusenko, V.N. Borisenko, F. Dworschak, U. Dedek, Phys Rev B Condens. Matter 64, 092513 (2001). https://doi.org/10.1103/PhysRevB. 64.092513

34. G.Y. Khadzhai, N.R. Vovk, R.V. Vovk, Low Temp. Phys. 40(6), 488 (2014). https://doi.org/10.1063/1.4881197

35. R. Vovk, N. Vovk, G. Khadzhai, I. Goulatis, A. Chroneos, Solid State Commun. 190, 18 (2014). https://doi.org/10.1016/ j.ssc.2014.04.004

36. R.V. Vovk, G.Y. Khadzhai, O.V. Dobrovolskiy, Appl. Phys. A-Mater. 117, 997-1002 (2014). https://doi.org/10.1007/s00 339-014-8670-2

37. S. Badoux, W. Tabis, F. Lalibert'e, G. Grissonnanche, B. Vignolle, D. Vignolles, J. Béard, D.A. Bonn, W.N. Hardy, R. Liang, N. Doiron-Leyraud, L. Taillefer, C. Proust, Nature 531, 210 (2016). https://doi.org/10.1038/nature16983

38. T.A. Friedmann, J.P. Rice, J. Giapintzakis, D.M. Ginsberg, Phys. Rev. B Condens. Matter 39, 4258 (1989). https://doi. org/10.1103/PhysRevB.39.4258

39. A.L. Solovjov, L.V. Omelchenko, R.V. Vovk, O.V. Dobrovolskiy, Z. Nazyrov, S. Kamchatnaya, D. Sergeyev, Phys. B 493, 58 (2016). https://doi.org/10.1016/j.physb.2016.04.015

40. J.M. Valles, A.E. White, K.T. Short, R.C. Dynes, J.P. Garno, A.F.J. Levi, M. Anzlowar, K. Baldwin, Phys Rev B Condens. Matter 39, 11599 (1989). https://doi.org/10.1103/PhysRevB. 39.11599

41. R.V. Vovk, Z.F. Nazyrov, I.L. Goulatis, A. Chroneos, Phys. C 485, 89 (2013). https://doi.org/10.1016/j.physc.2012.09.017

42. P.W. Anderson, Phys. Rev. Lett. 67, 2092 (1991). https://doi. org/10.1103/PhysRevLett.67.2092

43. R.V. Vovk, M.A. Obolenskii, A.V. Bondarenko, I.L. Goulatis, A.V. Samoilov, A. Chroneos, V.M.P. Simoes, J Alloy Compd. 464(1-2), 58 (2008). https://doi.org/10.1016/j.jallcom.2007. 10.040

44. J. Ashkenazi, J. Supercond. Nov. Magn. 24(4), 1281 (2011). h ttps://doi.org/10.1007/s10948-010-0823-8
45. G.Y. Khadzhai, Y.V. Litvinov, R.V. Vovk, S.F. Zdorovko, I.L. Goulatis, A. Chroneos, J. Mater. Sci. Mater. Electron. 29(9), 7725 (2018). https://doi.org/10.1007/s10854-018-8768-y

46. Y.V. Litvinov, R.V. Vovk, O.V. Dobrovolskiy, Phys. C 573, 1353645 (2020)

47. R.V. Vovk, G.Y. Khadzhai, O.V. Dobrovolskiy, Solid State Commun. 204, 64 (2015). https://doi.org/10.1016/j.ssc.2014. 12.008

48. M.A. Obolenskii, R.V. Vovk, A.V. Bondarenko, N.N. Chebotaev, Low Temp. Phys. 32(6), 571 (2006). https://doi.org/10. $1063 / 1.2215373$

49. T. Siegrist, S. Sunshine, D.W. Murphy, R.J. Cava, S.M. Zahurak, Phys. Rev. B Condens. Matter 35, 7137 (1987). h ttps://doi.org/10.1103/PhysRevB.35.7137

50. W.E. Lawrence, S. Doniach, in Proceedings of the 12th International Conference on Low Temperature Physics, ed. by E. Kanda (Keigaku, Tokyo, 1970)

51. L.G. Aslamasov, A.I. Larkin, Phys. Lett. A 26(6), 238 (1968). https://doi.org/10.1016/0375-9601(68)90623-3

52. G.D. Chryssikos, E.I. Kamitsos, J.A. Kapoutsis, A.P. Patsis, V. Psycharis, A. Koufoudakis, C. Mitros, G. Kallias, E. Gamari-Seale, D. Niarchos, Phys. C 254(1-2), 44 (1995). h ttps://doi.org/10.1016/0921-4534(95)00553-6

53. R.V. Vovk, M.A. Obolenskii, Z.F. Nazyrov, I.L. Goulatis, A. Chroneos, V.M. Pinto Simoes, J. Mater. Sci. Mater. Electron. 23(6), 1255 (2012). https://doi.org/10.1007/s10854-011-058 $2-8$

54. R.V. Vovk, A.A. Zavgorodniy, M.A. Obolenskii, I.L. Goulatis, A. Chroneos, V.M.P. Simoes, Mod. Phys. Lett. B 24(22), 2295 (2010). https://doi.org/10.1142/S0217984910024675

55. C.A. Downing, M.E. Portnoi, Nat. Commun. 8(1), 897 (2017). https://doi.org/10.1038/s41467-017-00949-y

56. P.J. Curran, V.V. Khotkevych, S.J. Bending, A.S. Gibbs, S.L. Lee, A.P. Mackenzie, Phys. Rev. B Condens. Matter 84, 104507 (2011). https://doi.org/10.1103/PhysRevB.84.104507

57. A.I. Bezuglyj, V.A. Shklovskij, V.V. Kruglyak, R.V. Vovk, Phys. Rev. B 100, 214409 (2019)

58. A. Bezyglyj, V. Shklovskij, V. Kruglyak, R.V. Vovk, Phys Rev B 99, 134428 (2019)

59. N. Kuganathan, P. Iyngaran, R. Vovk, A. Chroneos, Sci. Rep. 9(1), 4394 (2019). https://doi.org/10.1038/s41598-019-4087 $8-\mathrm{y}$

Publisher's Note Springer Nature remains neutral with regard to jurisdictional claims in published maps and institutional affiliations. 